\title{
Internationalising Singapore Medicine
}

\section{INTRODUCTION}

Singapore is now internationally accepted as a good model for economic development, good governance and clean government. Our extensive trade with the rest of the world, and transportation and communication links with most countries enable us to play a useful role in providing high-end services to many nations. Our excellent financial services, logistics, communications, transportation, tourism, professional services, education and healthcare enable Singapore to enjoy a larger mindshare among people internationally, thus attracting them here to avail themselves of these services.

Of these services, I believe healthcare and education, when properly delivered, engender the most goodwill, attachment and fond memories. When a child is delivered to a barren couple, sight is restored to the blind, coronary arteries are widened and cancer is removed, patients and their families are often grateful and develop fond memories of Singapore long after the event. Similarly, when someone is educated or trained here, he tends to develop an appreciation for and gratitude toward Singapore for many years afterwards.

\section{SINGAPORE AS A PRE-EMINENT REGIONAL HEALTHCARE HUB}

Building Singapore into an internationally renowned hub for healthcare will strengthen our position as an attractive global service hub. We had such an aspiration once, but somehow we have accepted that we are unable to compete against other regional healthcare centres. In the past two years, foreign patient numbers have not grown. However, I strongly believe that we should strengthen our resolve and redouble our efforts to rebuild Singapore as the pre-eminent healthcare hub of the region. I highlight four areas of development that need to work synergistically with each other, to enable Singapore to become such a healthcare hub.

\section{An internationally renowned healthcare service centre}

There are currently 18 public and private acute hospitals offering a total of 12,268 beds in Singapore. We now have 13,000 doctors, many of whom possess skills, talents and experience that are comparable to the best in the United Kingdom (UK), the United States (US), Europe and Japan. We also have about 40,000 nurses to assist doctors in the care of patients. We have enough medical facilities and medical manpower to cater to our ageing population, as well as serve foreigners seeking care here.

In 2002, the Healthcare Services Working Group under the Economic Review Committee aimed to attract one million foreign patients to Singapore by 2012. Such a patient load would have contributed $1 \%$ to the GDP and created 13,000 new jobs. ${ }^{(1)}$ Unfortunately, that target was not met; the rising costs in Singapore, together with the strengthening
Singapore dollar, made Singapore healthcare services more expensive than those offered by other countries, such as Thailand, Malaysia and India.

Today, these same factors continue to discourage pricesensitive patients from seeking healthcare in Singapore. It is clear that Singapore healthcare cannot compete on price alone. Our land, property and wages are much higher than those of other countries in the region. Singapore healthcare players can, however, compete on delivering better quality care and service, and being more professional and trustworthy. The healthcare services in the UK, Europe and the US are not cheap, yet hundreds of thousands of foreigners from all over the world seek care from Mayo Clinic, Cleveland Clinic, Memorial Sloan Kettering Cancer Center and Great Ormond Street Hospital each year. We should develop our hospitals and practices to such a high level of care and ethics that foreigners will be willing to pay a premium to seek healthcare in Singapore because of its high standards, quality, professionalism and trustworthiness. Furthermore, the Singapore medical profession and other healthcare players should make their fees fair and transparent. We must pay heed to the principle of ethical charging as laid down by the Court of Appeal in Susan Lim's case - that all medical practitioners in Singapore are subject to an ethical obligation to charge a fair and reasonable fee for their services, such obligation being an intrinsic aspect of the medical profession. ${ }^{(2)}$

The Singapore Medical Council has now provided clear guidelines on what ethical charging means. The fees that medical practitioners charge "must be fair and reasonable and commensurate with the work actually done and the circumstances in which it is done", and we "must not charge fees of a level that would bring the profession into disrepute". ${ }^{(3)}$ Recently, the Ministry of Health $(\mathrm{MOH})$ has also sent feedback to doctors whose professional fees are unusually high compared to other doctors' charges for similar procedures in the private sector. I commend the ministry on this practice. I believe this will ensure that professional fees are fairer and more reasonable. It will also help to keep healthcare costs down in Singapore.

Hopefully, all healthcare players, both public and private, will work together to ensure that Singapore healthcare is known for its quality of care and service, excellence, professionalism and trustworthiness. In fact, the provision of high-standard, professional and trusted care is totally consistent and resonant with our national branding and aspiration.

\section{A leading healthcare training centre}

Singapore has long been a training centre for the region. Our universities and polytechnics have trained skilled manpower for our economy, while students from the region have obtained rigorous training and internationally recognised qualifications from our educational institutions. Some of these training 
courses are relevant to healthcare, and students from the region have benefitted from them. Our polytechnics have trained nurses and allied health personnel, and the medical schools of National University of Singapore and Nanyang Technological University have produced doctors that hail from countries in the region. There is also a postgraduate medical school that trains medical specialists. In addition, business schools here provide management training and Master of Business Administration courses with a healthcare emphasis.

In the past, many Singaporeans were sent by the $\mathrm{MOH}$ for specialist training or fellowships in the UK, Australia and the US. These overseas-trained doctors formed lasting friendships and bonds with their teachers and fellow trainees, which have often blossomed into professional collaborations upon their return to Singapore. Many of these scholars, having seen medicine practised in more advanced countries, have returned to help elevate the standard of medical practice and care in Singapore. Singaporeans from all sections of society have benefited from the resultant improvement in healthcare systems and standards.

Likewise, when Singapore becomes an acknowledged training centre for healthcare manpower, we will become the reference point used as a benchmark for high quality and standards. In time, people from the region will also benefit from the improvements that their returning trainees will bring to their healthcare systems. Moreover, doctors from the region are more likely to refer their patients who have complicated and complex medical problems to the Singapore mentors and professors who trained them. Similarly, when our medical experts travel to countries in the region to conduct professional training, workshops, seminars or lectures in their respective fields, they project the good name of Singapore and promote Singapore as a leading healthcare service centre.

\section{An advanced healthcare research \& development centre}

In 2002, Singapore embarked on its biomedical innovation drive in earnest with the formation of the Agency for Science, Technology and Research (A*STAR). Besides setting aside space for laboratories at Biopolis and Fusionopolis, A*STAR sent 1,000 young people abroad to prepare and train them to provide the skills for such an undertaking. Today, the deliverables are a thriving biotech research and technology (R\&D) ecosystem, with $R \& D$ and production in pharmaceuticals, devices and healthcare information technology (IT) producing an annual output of around SGD 30 billion.

Research institutes such as the Genome Institute of Singapore and Institute of Molecular and Cell Biology, as well as the research centres of Merck Sharp \& Dohme, GlaxoSmithKline and Chugai Pharmaceutical, are doing great research, publishing their work, registering patents and producing marketable products. A community of biomedical start-ups, venture capitalists, patent lawyers and financial advisors, each with proven ability to commercialise products resulting from their R\&D activities, have developed together. Such R\&D capacity and ecosystem not only adds depth and breadth to Singapore's development as an international healthcare hub, but also helps to internationalise Singapore healthcare. It is commendable that the government will invest SGD 19 billion under the Research Innovation and Enterprise 2020 Plan in the next few years. ${ }^{(4)}$

\section{Singapore healthcare companies venturing into the region}

Most Singapore healthcare companies have ventured out of the comfort of the Singapore market into the region. Some have set up medical facilities, such as clinics and hospitals, in joint venture or as solely owned entities. Some companies offer their hospital management expertise for a fee, while others also take on the risk of ownership. A quick survey shows that Singapore healthcare companies have a presence in 14 countries within the region.

With your indulgence, I would like to share the regional experience of the Raffles Medical Group (RMG) with you, knowing that our experience may not be applicable to everyone. We are a Singapore homegrown company with a 41-year history. The RMG is now a group practice with 380 multispecialty physicians and 2,000 supporting staff. Today, we have medical practices in 13 Asian cities and count more than 2.2 million people as our patients. We are also a member of the Mayo Clinic Care Network. Raffles Hospital was opened in Singapore in 2001. Today, one-third of the patients seeking care at Raffles Hospital are foreigners who come from 120 countries. With the Raffles Hospital extension, the hospital will have $70 \%$ more space to expand its services.

Our regional hospitals - the 700-bed Raffles Hospital Chongqing and 400-bed Raffles Hospital Shanghai - will open in the fourth quarter of 2018 and the second half of 2019, respectively. Both of these hospitals will be led initially by Raffles physicians from Raffles Hospital Singapore, but we will progressively co-opt other physicians, as well as the leadership, into the regional practice. We expect to grow the group practice to one with 1,000 multispecialty staff physicians by 2020. This practice will be supported by 4,000 staff comprising healthcare managers, nurses, allied health professionals and other support staff.

Besides providing healthcare services of international standards, we shall also undertake training and research activities as we grow these hospitals. We intend to manage our Raffles Hospitals overseas to enable our physicians and staff to care for all our patients with compassion, commitment and excellence in a team-based manner, delivering real and lasting value to our patients and their families. The core values and creed of the RMG are best summed up in the mnemonic CCETV.

We measure ourselves by the quality of care and service we provide. The profit we make is but a measure of the efficiency of our staff and management system. We venture into the region in the belief that there are many people in the region who desire to have better healthcare and are prepared to pay for professional and ethical medical service. We believe that by doing so, we are providing all our stakeholders the opportunity to grow and to contribute to better health for more communities.

You may wonder how we can achieve these things in a challenging environment like China. Indeed, the challenges are many. However, we are confident that the strengths of our group practice will ensure our success. Some of our medical 
directors and heads of services have volunteered to relocate to Chongqing when the hospital opens next year. Additionally, other international specialists, as well as specialists recruited from within China, will be brought to Raffles Hospital Singapore for observation and training before they start practising in our regional hospitals. Here, they will be immersed in our ecosystem, where they can observe how we treat our patients, conduct peer reviews and audit ourselves. In this way, new joiners are shown how Raffles physicians deliver high quality healthcare compassionately and professionally. Likewise, our nurse managers, nursing directors and hospital managers have volunteered to take up the challenge to manage our hospital in Chongqing. International and China nurses and healthcare managers joining us in Chongqing will spend some months training in Singapore.

Such preparation and effort by the Raffles leadership are what it takes to enable us to plant our culture, ethos and brand of healthcare on foreign soil. Being profitable is not enough for us. We commit ourselves to deliver care our way - the Raffles way.

\section{ROLE OF THE PUBLIC SECTOR}

The public sector - with eight acute hospitals and eight speciality centres with a total of 10,400 beds, 3,300 specialists, 5,100 generalists and three medical schools - can and must play a leading role in developing Singapore into a renowned international healthcare hub.

Public sector hospitals have, as their priority, the provision of healthcare for Singapore's 5.5-million population. They have the capacity and scale to deliver care in large volumes, the capability to teach, train and develop medical manpower, and the ability to undertake R\&D activities. They also have a large number of generous donors and the resources to invest in beneficial and appropriate technologies. Because of the large public healthcare load, expensive facilities and technologies, if beneficial to patients, can be acquired, as the high demand justifies the acquisition.

Hence, the public sector should lead the way in medical education training at both the undergraduate and postgraduate levels, as well as in R\&D efforts, whereas private sector healthcare organisations can play complementary and supporting roles in these areas. However, in the area of serving foreign patients seeking care in Singapore, I would suggest that the public sector partner with private sector healthcare organisations. This is because foreign patients generally need a much greater degree of responsiveness from their providers and expect pampering and high-touch and -feel services, which the public sector may not be purposed for. Such partnerships can take many forms, but have to be on a sustainable basis and must not be at the expense of care provisioning for public sector patients. My belief is that such collaborations are best established between healthcare institutions if they are to be sustainable. The future is uncertain; therefore, I call upon the $\mathrm{MOH}$ and private players to explore such collaborations with open minds and fresh eyes.

In terms of venturing overseas to set up medical institutions, I opine that the public will be better served if our medical, nursing and managerial talents from the public sector focus their energies on looking after our own citizens in Singapore. Besides, it would be extremely embarrassing if monies meant for public healthcare in Singapore were to be lost while investing in healthcare ventures overseas. However, if the $\mathrm{MOH}$ is prepared to support Singapore private healthcare companies venturing overseas, it may consider granting some of its staff sabbatical or no pay leave for a period of up to one year to work overseas with such companies. This is similar to the gap year that Public Service Commission scholars are permitted to take. Not only will the staff and their families benefit from such overseas stints in terms of personal development and experience, but the institution's clinical practice may also be enriched by the clinical experience gained in a different community.

\section{FISCAL SUPPORT FROM THE GOVERNMENT}

As an internationally renowned healthcare centre, Singapore will attract more foreign patients, which will result in downstream benefits for the economy. It has been estimated that every dollar of direct foreign patient expenditure translates to an additional 92 cents for the Singapore economy, through spending on hotel accommodation, food, transportation and shopping. Other services like private banking and life insurance may also receive a boost. In view of this, it is perhaps time for the Government to consider implementing some fiscal measures in the coming Budget 2018 to promote this effort. These include:

(a) Goods and Services Tax (GST) exemption fully at source for all foreign patient expenses at hospitals and clinics in Singapore. Currently, GST rebate applies only to medication and consumables brought out of Singapore. In Malaysia, Thailand, India and some European countries (including the UK), GST or Value Added Tax is exempted for foreign patients. Since there is recognition of the need for some GST rebate for foreign patients, we should widen the ambit to include the whole treatment at hospitals and clinics, and make it more convenient for the foreign patient by exempting GST at source. Such a measure will reduce the costs of medical treatment by $7 \%$ for foreign patients.

(b) Corporate tax exemption on profits at Singapore hospitals accrued from foreign patients. Such a measure, if adopted, will enable healthcare players to reduce their prices by a few more percentage points. With the tax exemption, they may also be encouraged to lower their margins to be even more competitive.

(c) GST exemption on fees and corporate tax exemption from profit accrued from foreign healthcare trainees. Such support will boost healthcare training in Singapore and attract more healthcare trainees from the region.

(d) Double deduction on approved R\&D investments in Singapore by private sector healthcare organisations. This measure may boost R\&D efforts in Singapore and enable healthcare start-ups to attract more private sector healthcare investors. Private sector R\&D units that are involved in applied research may also stand a greater chance of commercialising their discoveries. 


\section{CONCLUSION}

Today, Singapore is already recognised as a regional healthcare hub, but our status is threatened. We need to do more to compete with other regional healthcare centres. We can only succeed if we put our strengths and efforts together. To ensure success, $\mathrm{MOH}$ and Singapore healthcare players should work together and, wherever possible, develop synergies in the four areas of clinical service, training, research and hospital management. With the attraction of Singapore's other world-class services in finance, communications, IT, logistics, and professional and business services, a strong standing as the pre-eminent healthcare centre in the region will help make Singapore an even more compelling global service hub. This will certainly contribute to Singapore's continued relevance to the world, and our long-term survival and security as an independent, sovereign nation.

\section{REFERENCES}

1. Ministry of Trade and Industry, Singapore. Reports of the Economic Review Committee. Developing Singapore as the Healthcare Services Hub in Asia. 1 February 2003. Available at: https://www.mti.gov.sg/ResearchRoom/Pages/ Reports-of-the-Economic-Review-Committee.aspx. Accessed November 27, 2017.

2. Lim Mey Lee Susan v Singapore Medical Council [2013] 3 SLR 914.

3. Singapore Medical Council. Ethical Code and Ethical Guidelines, 2016: 60. Available at: http://www.healthprofessionals.gov.sg/content/hprof/smc/en/ topnav/guidelines/ethical_code_and_ethical_guidelines.html. Accessed November 5, 2017.

4. National Research Foundation. Research Innovation and Enterprise 2020 Plan. Available at: https://www.nrf.gov.sg/rie2020. Accessed November 27, 2017.

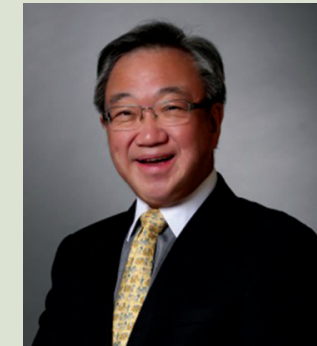

\section{About the Lecturer}

Dr Loo Choon Yong is the Executive Chairman of Raffles Medical Group. He co-founded the Group in 1976 and was appointed to his current position in 1997 when the Group was listed on the Singapore Stock Exchange. He is also the Chairman of Asian Medical Foundation Ltd and Raffles Health Insurance Pte Ltd. In the area of public service, Dr Loo was appointed by the President of Singapore in 2015 as the Non-Resident Ambassador to the Republic of Poland. Prior to this, he was the Non-Resident Ambassador to the Italian Republic between 2006 and 2015. He was also the appointed Chairman of JTC Corporation from January 2013. He was previously the Chairman of Sentosa Development Corporation and Sentosa Golf Club.

The 2017 SMA Lecture was delivered on 4 November 2017 at the Grand Copthorne Waterfront. The citation of Dr Loo Choon Yong was delivered by Prof Walter TL Tan, Adjunct Professor of Surgery, National University of Singapore and Medical Director, Raffles Hospital. A copy of the citation was published in the December 2017 issue of the SMA News. 